Supporting Information

\title{
Effects of Selective Alkoxy Side Chain Position in Quinoxaline- Based Polymer Acceptors on the Performance of All-Polymer Solar Cells
}

Hoseon You, ${ }^{\dot{t}, \dagger}$ Seungjin Lee,,$\stackrel{+}{\dagger}$ Donguk Kim, ${ }^{\S}$ Hyunbum Kang, ${ }^{\dagger}$ Chulhee Lim,,$^{\dagger}$ Felix Sunjoo $\mathrm{Kim}^{*}{ }^{*}$ and Bumjoon J. Kim ${ }^{*}$,

${ }^{\dagger}$ Department of Chemical and Biomolecular Engineering, Korea Advanced Institute of Science and Technology (KAIST), Daejeon 34141, Republic of Korea

$\S_{\text {School of Chemical Engineering and Materials Science, Chung-Ang University (CAU), Seoul }}$ 06974, Republic of Korea

*E-mail: fskim@cau.ac.kr, bumjoonkim@kaist.ac.kr 


\section{Table of Contents}

\section{Methods}

\section{Supplementary Figures}

- Figure S1. ${ }^{1} \mathrm{H}$ NMR spectra of (a-d) compound 1-4 and (e-f) QxCN-based polymers with alkoxy side chains at meta and para positions, respectively.

- Figure S2. GPC traces for QxCN-based polymers with 1,2-dichlorobenzene as an eluent.

- Figure S3. Cyclic voltammogram of (a) reduction and (b) oxidation for QxCN-based polymers and $\mathrm{PBDB}-\mathrm{T}$ versus $\mathrm{Fc} / \mathrm{Fc}^{+}$, and (c) ferrocene.

- Figure S4. Trimer structures and their calculated energy levels of the frontier molecular orbitals for (a) $\mathrm{P}(\mathrm{Q} x \mathrm{CN}-\mathrm{T} 2)-m$ and (b) $\mathrm{P}(\mathrm{QxCN}-\mathrm{T} 2)-p$.

- Figure S5. (a) Second cycle DSC and (b) TGA curves for QxCN-based polymers.

- Figure S6. (a) Transfer curves $\left(I_{\mathrm{D}}-V_{\mathrm{G}}\right)$ and (b) output curves $\left(I_{\mathrm{D}}-V_{\mathrm{D}}\right)$ of field-effect transistors made of QxCN-based polymers.

- Figure S7. $J-V$ characteristics of all-PSCs in the dark.

- Figure S8. (a) RSoXS profiles and AFM height images of (b) $\mathrm{P}(\mathrm{Q} x \mathrm{CN}-\mathrm{T} 2)$, (c) $\mathrm{P}(\mathrm{QxCN}-$ $\mathrm{T} 2)-m$, and (d) $\mathrm{P}(\mathrm{QxCN}-\mathrm{T} 2)-p$ blend films.

\section{Supplementary Tables}

- Table S1. Detailed GIXS (100) peak information for in-plane direction and (010) peak information for out-of-plane direction in pristine films of QxCN-based polymers.

- Table S2. Electron mobilities measured using SCLC devices based on blend films of QxCN-based $P_{\mathrm{AS}}$ with PBDB-T. 


\section{Methods}

\section{Characterizations}

All reactions were conducted under nitrogen or argon condition. The ${ }^{1} \mathrm{H}$ nuclear magnetic resonance $\left({ }^{1} \mathrm{H}\right.$ NMR) was measured by an NMR instrument (Bruker) with $400 \mathrm{MHz}$ using $\mathrm{CDCl}_{3}$ as a solvent. The number-average molecular weights $\left(M_{\mathrm{n}}\right)$ and their dispersity values $(\nexists)$ for the synthesized polymers were obtained by gel permeation chromatography (GPC) using 1,2-dichlorobenzene $\left(10 \mathrm{mg} \mathrm{mL}^{-1}\right)$ at $80{ }^{\circ} \mathrm{C}$. The GPC calibration was carried out by polystyrene standards. Differential scanning calorimetry (DSC) measurements were conducted under nitrogen condition using a TA DSC 25 instrument; heating/cooling rates were $10{ }^{\circ} \mathrm{C}$ $\min ^{-1}$. The UV-Vis absorption characteristics of thin films were acquired from UV-1800 (Shimadzu Scientific Instruments). Polymer solutions in chlorobenzene (CB) $\left(10 \mathrm{mg} \mathrm{mL}^{-1}\right)$ were spin-cast on glass substrates (3000 rpm for $40 \mathrm{~s}$, ramp time: $0.1 \mathrm{~s}$ ) to prepare the thin films for the UV-Vis measurements. Electrochemical characteristics were analyzed by cyclic voltammetry (CV) measurements using a conventional three-electrode system (Pt disk as a working electrode, $\mathrm{Pt}$ wire as a counter electrode, and $\mathrm{Ag}$ wire as a quasi-reference electrode) in anhydrous acetonitrile with $0.1 \mathrm{M}$ tetrabutylammonium hexafluorophosphate. The CV measurements were calibrated with $\mathrm{Fc} / \mathrm{Fc}^{+}$redox couple (potential scan rate: $50 \mathrm{mV} \mathrm{s}^{-1}$ ) and it was assumed that the absolute energy level of $\mathrm{Fc} / \mathrm{Fc}^{+}$is $-4.80 \mathrm{eV}$. Grazing incidence wideangle X-ray scattering (GIXS) experiment was conducted at the 3C beamline of the Pohang Accelerator Laboratory (South Korea). The polymer films for GIXS measurements were prepared by spin-coating a solution of polymer in $\mathrm{CB}\left(10 \mathrm{mg} \mathrm{mL}^{-1}\right)$ on bare silicon substrates at $3000 \mathrm{rpm}$ for $40 \mathrm{~s}$ with a ramp time of $0.1 \mathrm{~s}$. The incident X-ray had a wavelength of 1.2301 $\AA$. The incidence angle was about $0.12^{\circ}$ for complete penetration of X-ray through the polymer film. Resonant soft X-ray scattering (RSoXS) experiments were conducted at BL 11.0.1.2 in 
the Advanced Light Source (USA). Atomic force microscopy (AFM) experiments were carried out using NX10 instrument (Park Systems) with a non-contact mode. The photoluminescence (PL) spectra were measured using a Horiba Jobin Yvon NanoLog spectrophotometer with the excitation wavelength of $750 \mathrm{~nm}$. Density functional theory (DFT) calculation was conducted with the ORCA 4.2.1 package. ${ }^{2}$ Geometry was optimized at the level of BP86/def2-TZVP with D3BJ. Molecular orbital energy levels were then calculated at the PBE0/def2-TZVP level with D3BJ. RIJCOSX approximation was used to accelerate the calculation. All alkoxy side chains were replaced with methoxy groups to reduce the calculation time.

\section{Materials}

Potassium $\quad$ carbonate $\quad(>99.0 \%), \quad N, N$-dimethylformamide $\quad(99.8 \%)$, tris(dibenzylideneacetone)dipalladium(0) $\left(\mathrm{Pd}_{2}(\mathrm{dba})_{3}\right)(97 \%)$, tri $\left(o\right.$-tolyl)phosphine $\left(\mathrm{P}(o \text {-tol })_{3}\right)$ (97\%) were purchased from Sigma-Aldrich. 3,3'-Dimethoxybenzil (99\%) and 4,4'dimethoxybenzil (99\%) were purchased from Alfa Aesar. 2-Hexyldecylbromide (99\%) and 5,5'-bis(trimethylstannyl)-2,2'-bithiophene were purchased from Suna Tech. Acetic acid (99.5\%) and $\mathrm{HBr}$ aqueous solution (48 wt. \%) were purchased from Samchun Chemical. Poly[(2,6-(4,8-bis(5-(2-ethylhexyl)thiophen-2-yl)-benzo[1,2-b:4,5-b']dithiophene))-alt-(5,5(1',3'-di-2-thienyl-5',7'-bis(2-ethylhexyl)benzo[1',2'-c:4', $\left.5^{\prime}-\mathrm{c}^{\prime}\right]$ dithiophene-4,8-dione))] (PBDB-T) was purchased from Brilliant Matters. 4,5-Diamino-3,6-dibromophthalonitrile, $\mathrm{P}(\mathrm{QxCN}-\mathrm{T} 2)$, and poly[(9,9-bis(3'-((N,N-dimethyl)-N-ethylammonium)propyl)-2,7-fluorene)alt-5,5'-bis(2,2'-thiophene)-2,6-naphthalene-1,4,5,8-tetracabox ylic- $N, N^{\prime}$-di(2ethylhexyl)imide]dibromide (PNDIT-F3N-Br) were prepared according to the reported procedures. ${ }^{3-4}$ All of the chemicals were used as received. 


\section{Synthesis procedures and results for monomers and polymers}

1,2-bis(3-((2-hexyldecyl)oxy)phenyl)ethane-1,2-dione (1): Compound 1 was synthesized as per the general procedure, using 3,3'-dimethoxybenzil (4.0 g, $15 \mathrm{mmol})$, potassium carbonate (4.7 g, $34 \mathrm{mmol})$, and 2-hexyldecylbromide (10.4 g, $34 \mathrm{mmol})$. Yield: 57\%, ${ }^{1} \mathrm{H} \mathrm{NMR}(400 \mathrm{MHz}$, $\left.\mathrm{CDCl}_{3}\right): \delta(\mathrm{ppm}) 7.52(\mathrm{~s}, 2 \mathrm{H}), 7.45(\mathrm{~d}, J=8 \mathrm{~Hz}, 2 \mathrm{H}), 7.37(\mathrm{t}, J=12 \mathrm{~Hz}, 2 \mathrm{H}), 7.20(\mathrm{~d}, J=12$ $\mathrm{Hz}, 2 \mathrm{H}), 3.91(\mathrm{~d}, J=8 \mathrm{~Hz}, 4 \mathrm{H}), 1.79(\mathrm{~m}, 2 \mathrm{H}), 1.27(\mathrm{~m}, 48 \mathrm{H}), 0.87(\mathrm{~m}, 12 \mathrm{H})$.

1,2-bis(4-((2-hexyldecyl)oxy)phenyl)ethane-1,2-dione (2): Compound 2 was synthesized as per the general procedure, using 4,4'-dimethoxybenzil ( $4.0 \mathrm{~g}, 15 \mathrm{mmol})$, potassium carbonate (4.7 g, $34 \mathrm{mmol})$, and 2-hexyldecylbromide (10.4 g, $34 \mathrm{mmol})$. Yield: 65\%, ${ }^{1} \mathrm{H} \mathrm{NMR}(400 \mathrm{MHz}$, $\left.\mathrm{CDCl}_{3}\right): \delta(\mathrm{ppm}) 7.94(\mathrm{~d}, J=12 \mathrm{~Hz}, 4 \mathrm{H}), 6.96(\mathrm{~d}, J=12 \mathrm{~Hz}, 4 \mathrm{H}), 3.89(\mathrm{~d}, J=8 \mathrm{~Hz}, 4 \mathrm{H}), 1.77$ $(\mathrm{m}, 2 \mathrm{H}), 1.27(\mathrm{~m}, 48 \mathrm{H}), 0.88(\mathrm{~m}, 12 \mathrm{H})$.

QxCN-m monomer (3): Compound 3 was synthesized following the general procedure, using compound 1 (0.5 g, $0.7 \mathrm{mmol})$ and 4,5-diamino-3,6-dibromophthalonitrile $(0.2 \mathrm{~g}, 0.7 \mathrm{mmol})$. Yield: 51\%, ${ }^{1} \mathrm{H}$ NMR $\left(400 \mathrm{MHz}, \mathrm{CDCl}_{3}\right): \delta(\mathrm{ppm}) 7.31(\mathrm{~m}, 2 \mathrm{H}), 7.25(\mathrm{~m}, 4 \mathrm{H}), 7.02(\mathrm{~m}, 2 \mathrm{H})$, $3.72(\mathrm{~d}, J=8 \mathrm{~Hz}, 4 \mathrm{H}), 1.73(\mathrm{~m}, 2 \mathrm{H}), 1.75(\mathrm{~m}, 4 \mathrm{H}), 1.27(\mathrm{~m}, 48 \mathrm{H}), 0.88(\mathrm{~m}, 12 \mathrm{H})$. MALDITOF MS: calculated for $\mathrm{C}_{54} \mathrm{H}_{74} \mathrm{Br}_{2} \mathrm{~N}_{4} \mathrm{O}_{2}$ 968.42; found: 972.08 (M+).

QxCN-p monomer (4): Compound 4 was synthesized following the general procedure, using compound 2 (0.5 g, $0.7 \mathrm{mmol})$ and 4,5-diamino-3,6-dibromophthalonitrile (0.2 g, $0.7 \mathrm{mmol})$. Yield: 55\%, ${ }^{1} \mathrm{H}$ NMR $\left(400 \mathrm{MHz}, \mathrm{CDCl}_{3}\right): \delta(\mathrm{ppm}) 7.76(\mathrm{~d}, J=8 \mathrm{~Hz}, 4 \mathrm{H}), 6.92(\mathrm{~d}, J=8 \mathrm{~Hz}$, 
4H), $3.89(\mathrm{~d}, J=4 \mathrm{~Hz}, 4 \mathrm{H}), 1.80(\mathrm{~m}, 2 \mathrm{H}), 1.28(\mathrm{~m}, 48 \mathrm{H}), 0.88(\mathrm{~m}, 12 \mathrm{H})$. MALDI-TOF MS: calculated for $\mathrm{C}_{54} \mathrm{H}_{74} \mathrm{Br}_{2} \mathrm{~N}_{4} \mathrm{O}_{2}$ 968.42; found: $971.29(\mathrm{M}+)$.

P(QxCN-T2)-m: P(QxCN-T2)- $m$ was polymerized with compound 3 (200 mg, 0.206 mmol), 5,5'-bis(trimethylstannyl)-2,2'-bithiophene (101 mg, $0.206 \mathrm{mmol}), \mathrm{P}(o \text {-tol })_{3}(5.01 \mathrm{mg}, 0.016$ mmol), and $\mathrm{Pd}_{2}(\mathrm{dba})_{3}(3.77 \mathrm{mg}, 0.004 \mathrm{mmol})$ following the general procedure. Yield: $64 \%,{ }^{1} \mathrm{H}$ NMR (400MHz, $\left.\mathrm{CDCl}_{3}\right): \delta(\mathrm{ppm})$ 8.23-7.86 (br, 2H), 7.64-7.28 (br, 6H), 7.08-6.84 (br, 4H), 3.79-3.49 (br, 4H), 2.01-0.48 (br, 62H).

P(QxCN-T2)-p: P(QxCN-T2)- $p$ was polymerized with compound 4 (200 mg, $0.206 \mathrm{mmol}$ ), 5,5'-bis(trimethylstannyl)-2,2'-bithiophene (101 mg, $0.206 \mathrm{mmol}), \mathrm{P}(o \text {-tol })_{3}(5.01 \mathrm{mg}, 0.016$ mmol $)$, and $\mathrm{Pd}_{2}(\mathrm{dba})_{3}(3.77 \mathrm{mg}, 0.004 \mathrm{mmol})$ following the general procedure. Yield: $72 \%,{ }^{1} \mathrm{H}$ NMR (400MHz, $\left.\mathrm{CDCl}_{3}\right): \delta$ (ppm) 8.17-7.43 (br, 4H), 7.17-5.96 (br, 8H), 4.13-3.47 (br, 4H), 2.26-0.41 (br, 62H). 


\section{Fabrication of all-polymer solar cells (all-PSCs)}

All-PSCs with conventional type, where a device structure is indium tin oxide (ITO)/poly(3,4-ethylenedioxythiophene):poly(styrene sulfonate) (PEDOT:PSS)/active layer/ PNDIT-F3N-Br/Ag, were fabricated. The ITO layer coated on glass substrate was washed in an ultrasonic bath soaking in acetone and isopropanol, sequencially. After drying the cleaned substrates in an oven at $80{ }^{\circ} \mathrm{C}$, plasma treatment was conducted. PEDOT:PSS solution was spin-coated at the condition of $3000 \mathrm{rpm}$ for $40 \mathrm{~s}$ (ramp time: $0.1 \mathrm{~s}$ ) on top of the ITO-coated glass substrates, followed by baking at $165{ }^{\circ} \mathrm{C}$ for $15 \mathrm{~min}$ in air. The substrates were transferred to a nitrogen-filled glove box before deposition of polymer blends. The polymer blend solutions of $\mathrm{P}(\mathrm{Q} x \mathrm{CN}-\mathrm{T} 2), \mathrm{P}(\mathrm{QxCN}-\mathrm{T} 2)-m$, and $\mathrm{P}(\mathrm{QxCN}-\mathrm{T} 2)-p$ with $\mathrm{PBDB}-\mathrm{T}$ in $\mathrm{CB}$ (12 mg $\mathrm{mL}^{-1}$ ) were prepared by stirring with 3.0 vol\% of diphenylether as an additive on a hot plate at $80{ }^{\circ} \mathrm{C}$ for $3 \mathrm{~h}$. The optimized donor:acceptor ratios were 1.5:1 (w/w) for both $\mathrm{P}(\mathrm{QxCN}-\mathrm{T} 2)-m$ and $\mathrm{P}(\mathrm{QxCN}-\mathrm{T} 2)-p$ blends and 1:1 for a $\mathrm{P}(\mathrm{QxCN}-\mathrm{T} 2)$ blend. Polymer blends were spin-coated at $3000 \mathrm{rpm}$ for $40 \mathrm{~s}$ (ramp time: $0.1 \mathrm{~s}$ ) onto the ITO/PEDOT:PSS substrates. The thicknesses of $\mathrm{P}(\mathrm{QxCN}-\mathrm{T} 2), \mathrm{P}(\mathrm{Q} x \mathrm{CN}-\mathrm{T} 2)-m$, and $\mathrm{P}(\mathrm{QxCN}-\mathrm{T} 2)-p$ blend films were approximately $70 \mathrm{~nm}$. After thermal annealing of active layers at $130{ }^{\circ} \mathrm{C}$ for $10 \mathrm{~min}, 1 \mathrm{mg} \mathrm{mL}{ }^{-1}$ of PNDIT-F3N-Br solution in methanol was spin-coated at $2500 \mathrm{rpm}$ for $40 \mathrm{~s}$ (ramp time: $0.1 \mathrm{~s}$ ) on the top layer. Finally, Ag was deposited as top electrode using thermal evaporation under a high vacuum. The active area for the fabricated all-PSC devices was $0.164 \mathrm{~cm}^{2}$, which was measured by optical microscopy. The current density-voltage $(J-V)$ characteristics of the devices were evaluated using a solar simulator (K201 LAB55, McScience) and Keithley 2400 sourcemeasure unit under simulated irradiance of $100 \mathrm{~mW} \mathrm{~cm}^{-2}$ from a $150 \mathrm{~W}$ Xe short-arc lamp filtered by an air-mass $1.5 \mathrm{G}$ filter, which satisfies the Class AAA of the ASTM Standard. Light intensity of the solar simulator was calibrated with a Si reference cell (K801S-K302, 
McScience). External quantum efficiency (EQE) spectra were obtained using a spectral measurement system (K3100 IQX, McScience Inc.). This system is equipped with monochromatic light from a xenon arc lamp at $300 \mathrm{~W}$ filtered by an optical chopper (MC 2000 Thorlabs) and a monochromator (Newport). The estimated short-circuit current density $\left(J_{\mathrm{SC}}\right)$ values were calculated by integrating the product of the EQE multiplied by the AM 1.5G solar spectrum, and showed good agreement with the measured $J_{\mathrm{SC}}$, within $6 \%$ error.

\section{Space charge-limited current (SCLC) measurements}

Charge-carrier mobilities of pristine and blend films were measured by the SCLC method using device structures of $\mathrm{ITO} / \mathrm{ZnO} /$ active layer/LiF/Al (electron-only) and ITO/PEDOT:PSS/active layer/Au (hole-only). The blend films were prepared following the optimized conditions for all-PSC fabication. A range of 0-6 V was applied for the currentvoltage measurements, and the results were fitted to the Mott-Gurney equation:

$$
J_{S C L C}=\frac{9}{8} \varepsilon \varepsilon_{0} \mu \frac{V^{2}}{L^{3}}
$$

where $\varepsilon_{0}$ is the permittivity of free space $\left(8.85 \times 10^{-14} \mathrm{~F} \mathrm{~cm}^{-1}\right), \varepsilon$ is the relative dielectric constant of the active layer, $\mu$ is the charge carrier mobility, $V$ is the potential across the device $(V=$ $V_{\text {applied }}-V_{\mathrm{bi}}-V_{\mathrm{r}}(\mathrm{Eq} . \mathrm{S} 2)$, where $V_{\mathrm{bi}}$ is the built-in potential and $V_{\mathrm{r}}$ is the voltage drop caused by the resistance), and $L$ is the thickness of the active layer. 


\section{Organic field-effect transistor (OFET) measurements}

Lateral electron mobilities of all QxCN-based polymer films were investigated with bottom-gate top-contact OFET devices. Heavily p-doped Si wafer with a thermally grown 200 nanometer-thick oxide layer was sequentially washed by using ultra-sonication with demineralized water, acetone, and isopropyl alcohol for 15 min each. The surface of $\mathrm{SiO}_{2}$ dielectric layer was covered by a thin film of polymerized divinylsilane-bis-benzocyclobutene (BCB) to passivate the oxide surface and minimize electron trapping sites. ${ }^{5}$ All QxCN-based polymers were dissolved in anhydrous $\mathrm{CB}$ at $10 \mathrm{mg} \mathrm{mL}^{-1}$ and stirred at $80{ }^{\circ} \mathrm{C}$ before use. Polymer solutions were filtered through a syringe filter $(0.45 \mu \mathrm{m}$ polyvinylidene fluoride $)$ and spun on the substrate at $3000 \mathrm{rpm}$ for $60 \mathrm{~s}$. Gold electrodes $(50 \mathrm{~nm})$ were thermally evaporated onto the polymer films through a shadow mask. The $I-V$ characteristics of the devices were obtained by using HP4156A semiconductor parameter analyzer in a nitrogen-filled glovebox. Electron mobilities of polymer semiconductors were calculated using a saturation-regime equation for a metal-oxide-semiconductor field-effect transistor. The channel width $(W)$ and length $(L)$ were $1500 \mu \mathrm{m}$ and $150 \mu \mathrm{m}$, respectively. The areal capacitance $\left(C_{\mathrm{i}}\right)$ of BCBmodified $\mathrm{SiO}_{2}$ dielectric layer was measured to be $15 \mathrm{nF} \mathrm{cm} \mathrm{cm}^{-2}$ by using LCR meter (NF ZM2410). 


\section{Supplementary Figures and Tables}

(a) 1,2-bis(3-((2-hexyldecyl)oxy)phenyl)ethane-1,2-dione (1)

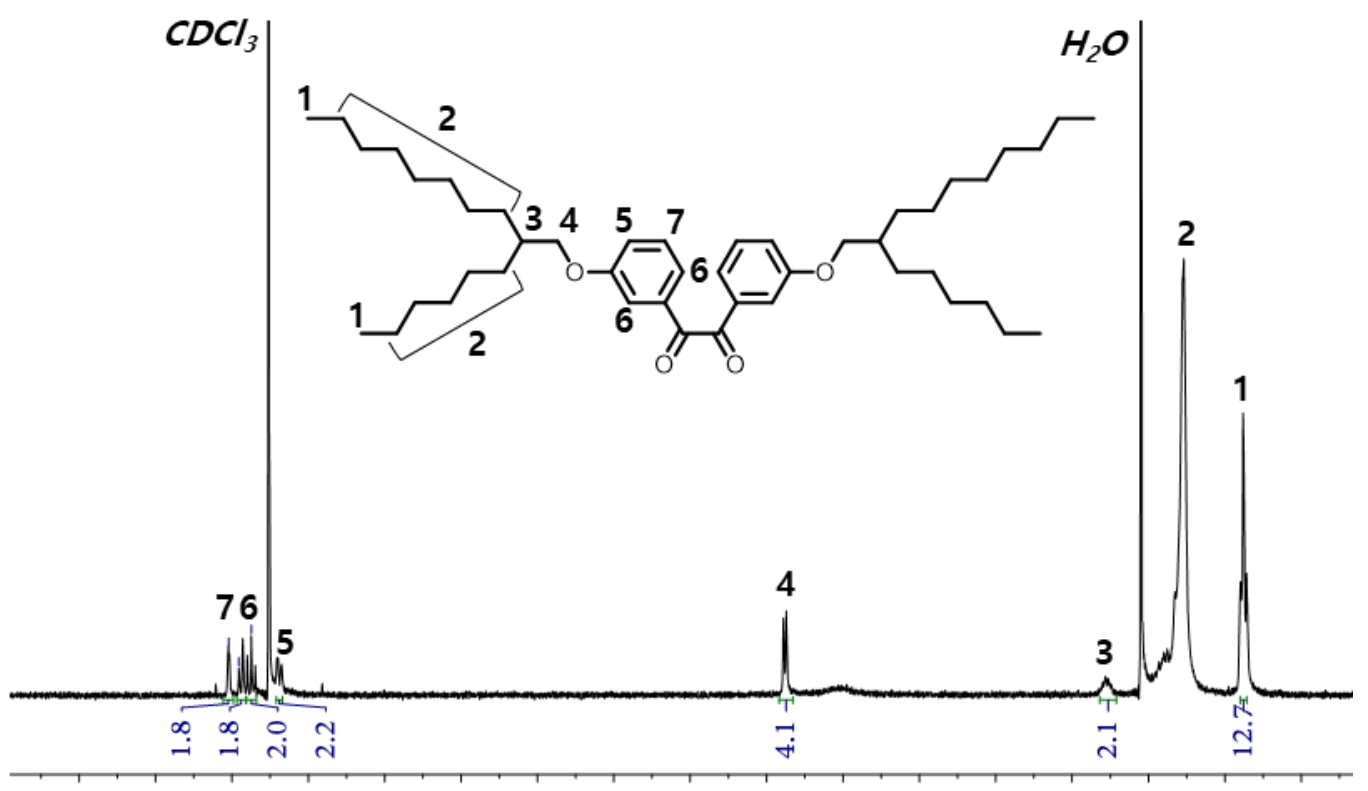

$\begin{array}{llllllllllllllllll}8.5 & 8.0 & 7.5 & 7.0 & 6.5 & 6.0 & 5.5 & 5.0 & 4.5 & 4.0 & 3.5 & 3.0 & 2.5 & 2.0 & 1.5 & 1.0 & 0.5\end{array}$

Chemical Shift (ppm)

(b) 1,2-bis(4-((2-hexyldecyl)oxy)phenyl)ethane-1,2-dione (2)

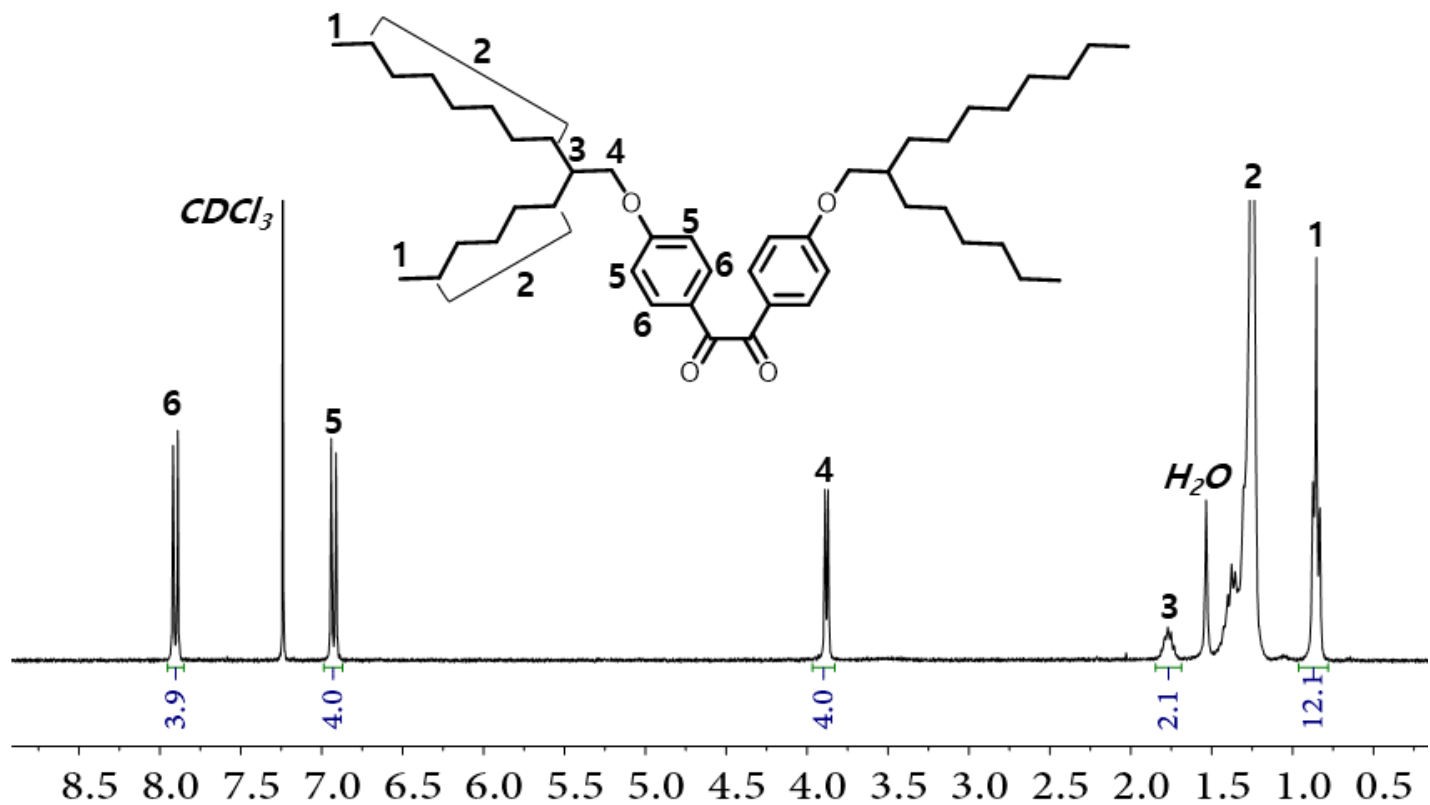

Chemical Shift (ppm) 
(c) QxCN-m monomer (3)

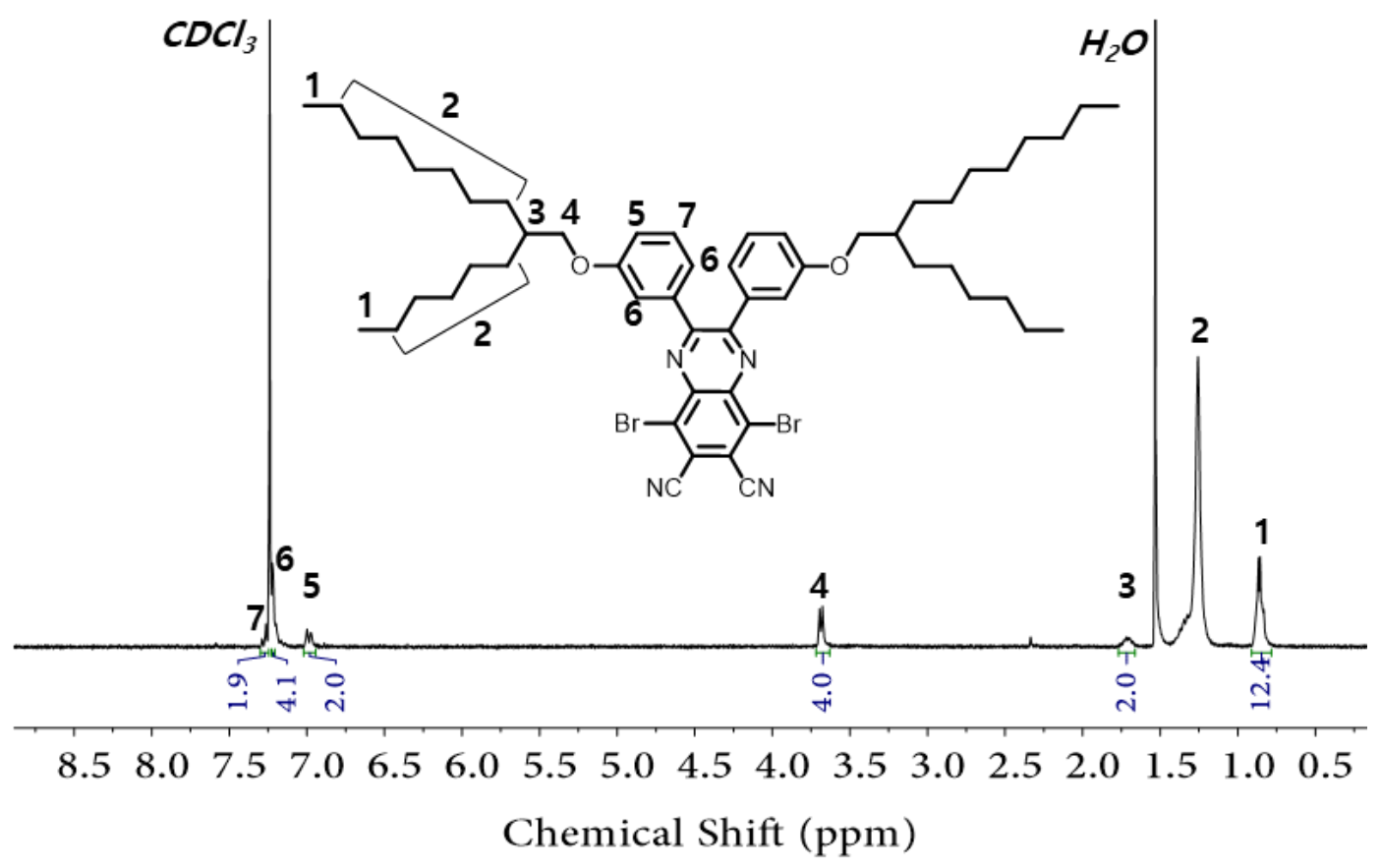

(d) QxCN-p monomer (4)

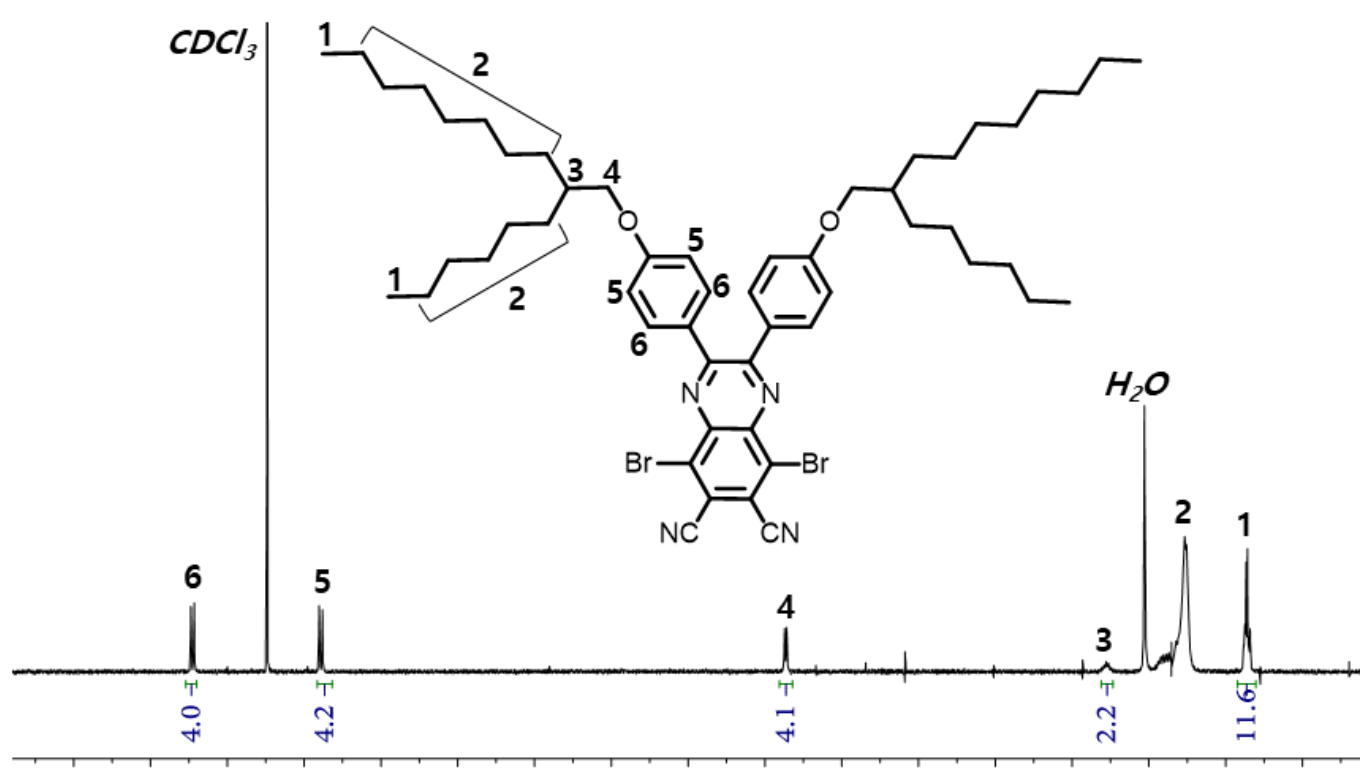

$\begin{array}{lllllllllllllllll}8.5 & 8.0 & 7.5 & 7.0 & 6.5 & 6.0 & 5.5 & 5.0 & 4.5 & 4.0 & 3.5 & 3.0 & 2.5 & 2.0 & 1.5 & 1.0 & 0.5\end{array}$

Chemical Shift (ppm) 
(e) $P(Q x C N-T 2)-m$

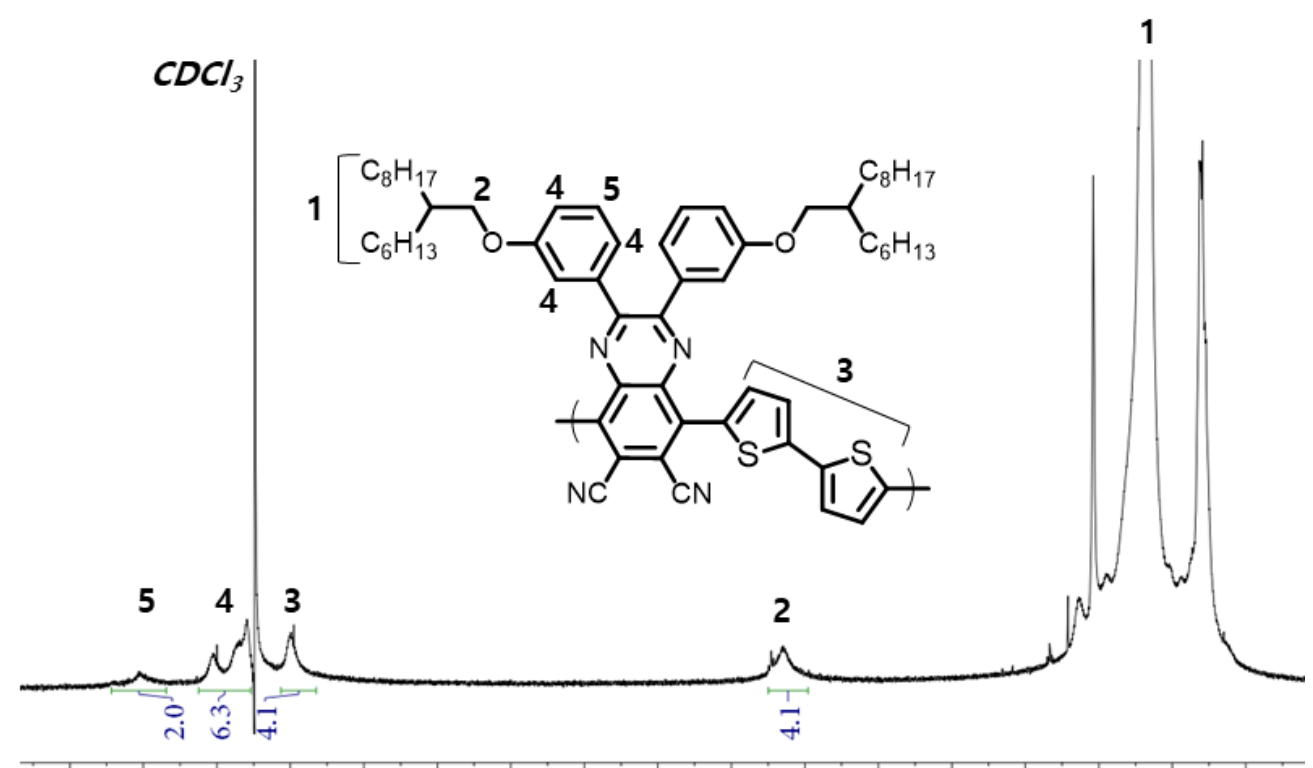

$\begin{array}{lllllllllllllllll}8.5 & 8.0 & 7.5 & 7.0 & 6.5 & 6.0 & 5.5 & 5.0 & 4.5 & 4.0 & 3.5 & 3.0 & 2.5 & 2.0 & 1.5 & 1.0 & 0.5\end{array}$

Chemical Shift (ppm)

(f) $\mathrm{P}(\mathrm{Q} \times \mathrm{CN}-\mathrm{T} 2)-p$

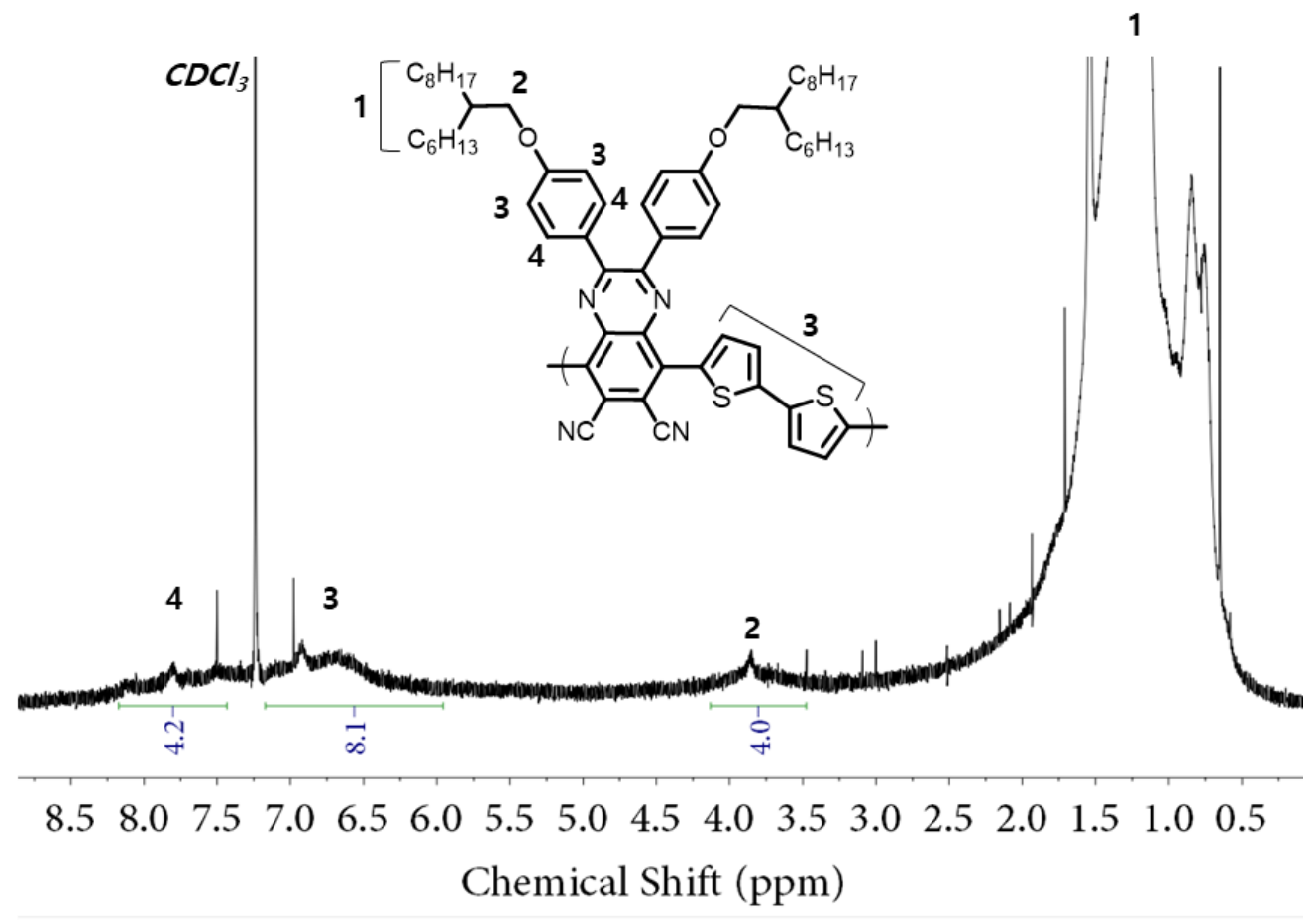

Figure S1. ${ }^{1} \mathrm{H}$ NMR spectra of (a-d) compound 1-4 and (e-f) QxCN-based polymers with alkoxy side chains at meta and para positions, respectively. 


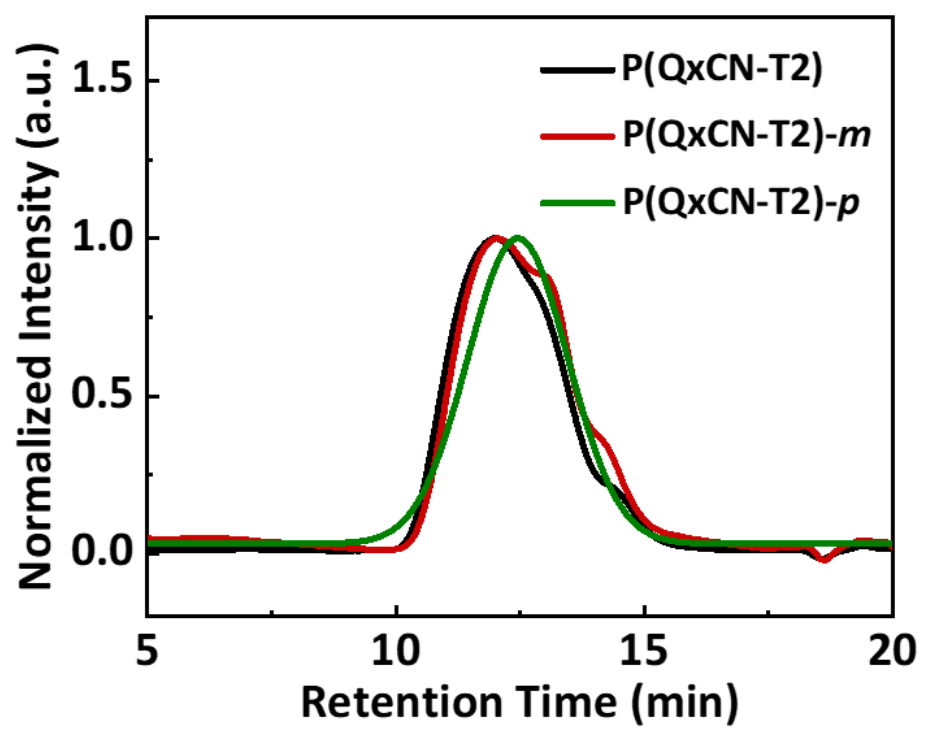

Figure S2. GPC traces for QxCN-based polymers with 1,2-dichlorobenzene as an eluent. 

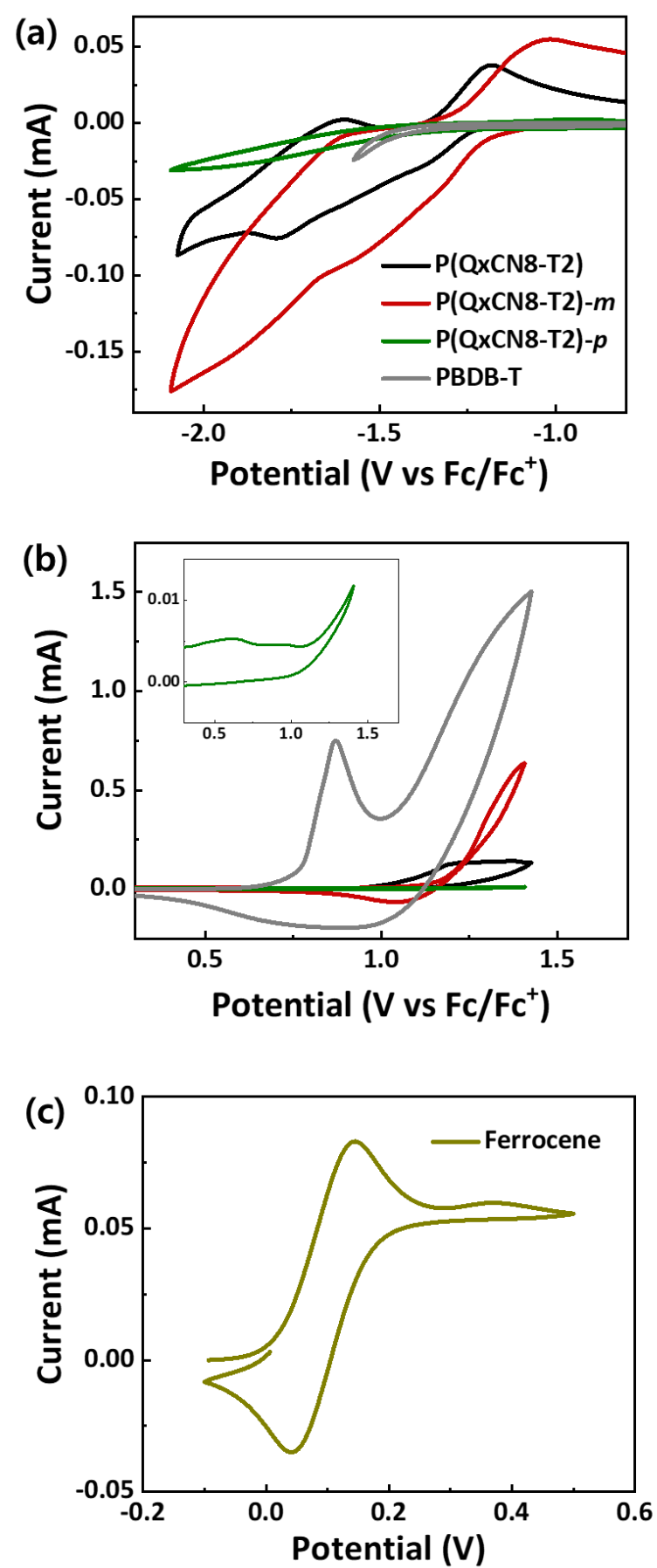

Figure S3. Cyclic voltammogram of (a) reduction and (b) oxidation for QxCN-based polymers and PBDB-T versus $\mathrm{Fc} / \mathrm{Fc}^{+}$, and (c) ferrocene. 

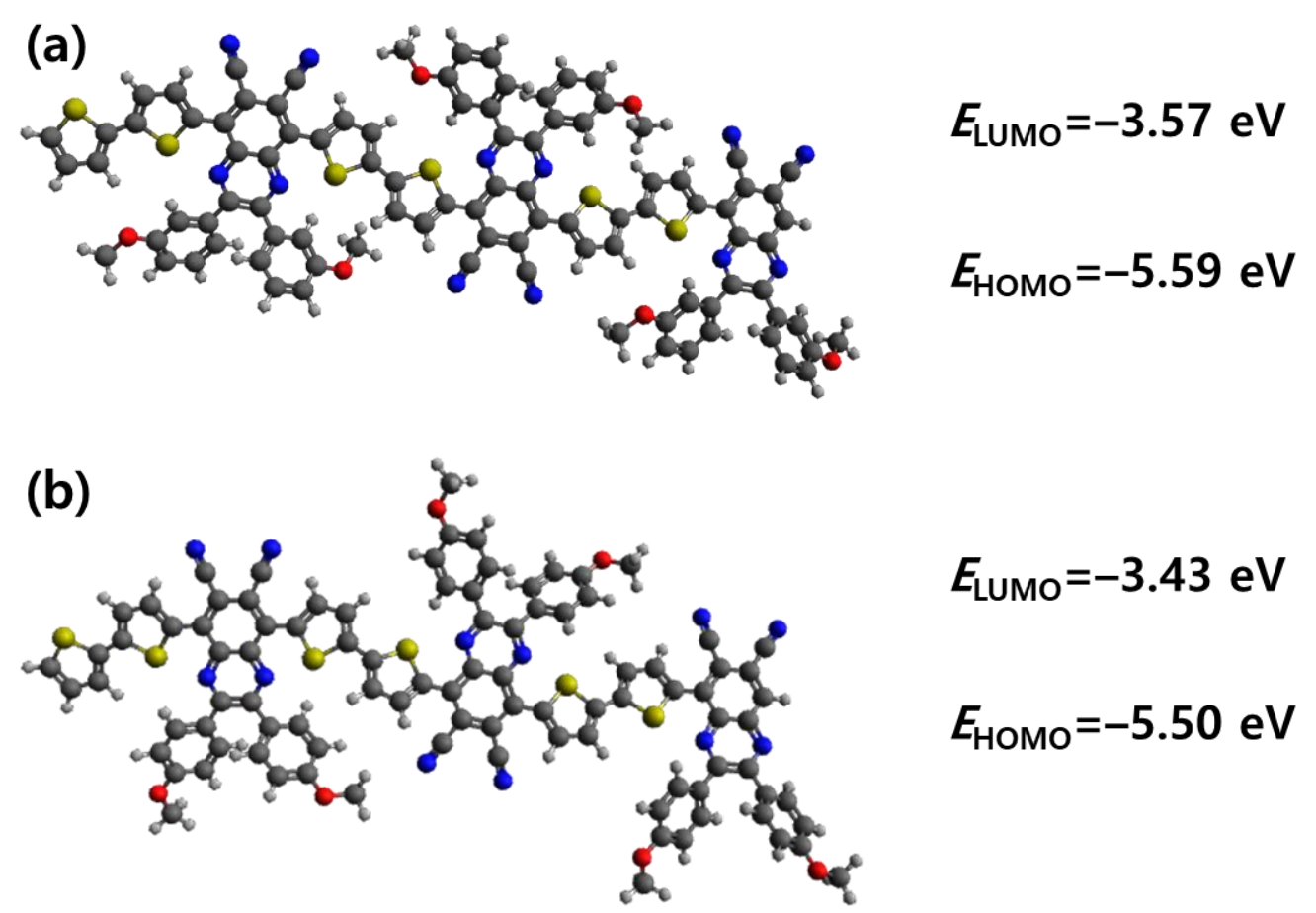

Figure S4. Trimer structures and their calculated energy levels of the frontier molecular orbitals for (a) $\mathrm{P}(\mathrm{Q} x \mathrm{CN}-\mathrm{T} 2)-m$ and (b) $\mathrm{P}(\mathrm{Q} x \mathrm{CN}-\mathrm{T} 2)-p$.

(a)

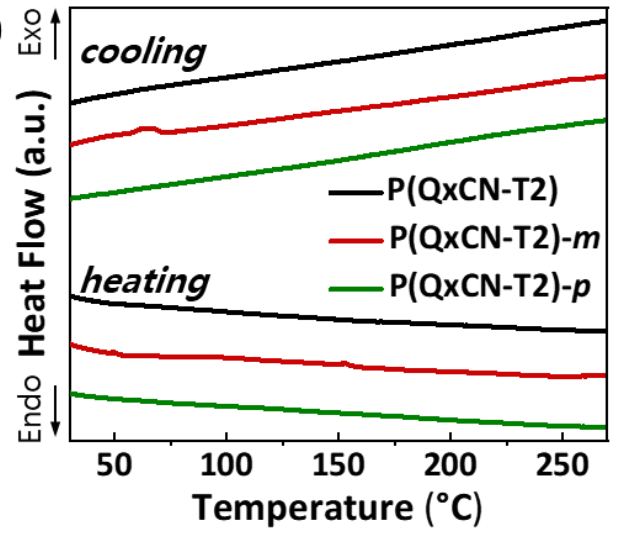

(b)

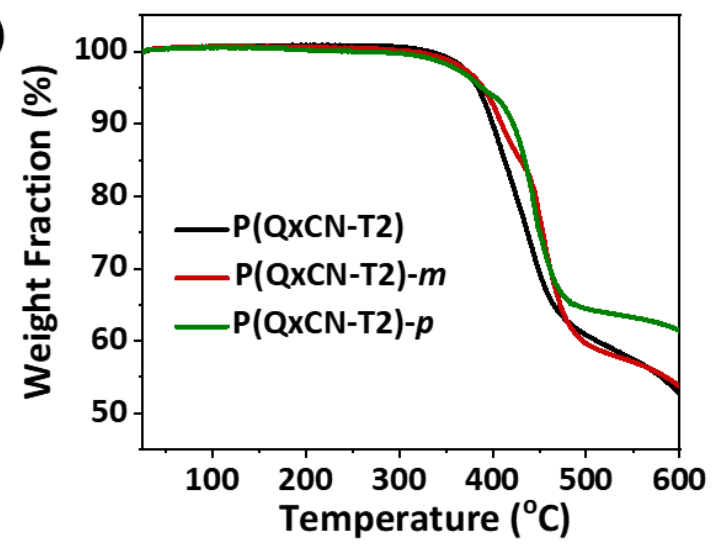

Figure S5. (a) Second cycle DSC and (b) TGA curves for QxCN-based polymers. 
Table S1. Detailed GIXS (100) peak information for in-plane direction and (010) peak information for out-of-plane direction in pristine films of QxCN-based polymers.

\begin{tabular}{llccc}
\hline \multirow{2}{*}{ Polymer } & \multicolumn{2}{c}{ In-plane direction } & \multicolumn{2}{c}{ Out-of-plane direction } \\
\cline { 2 - 5 } & $\begin{array}{l}q_{(100)} \\
\left(\AA^{-1}\right)\end{array}$ & $\begin{array}{c}d_{(100)} \\
(\AA)\end{array}$ & $\begin{array}{c}q_{(010)} \\
\left(\AA^{-1}\right)\end{array}$ & $\begin{array}{c}d_{(010)} \\
(\AA)\end{array}$ \\
\hline $\mathrm{P}(\mathrm{QxCN}-\mathrm{T} 2)$ & 0.22 & 29.02 & 1.67 & 3.72 \\
$\mathrm{P}(\mathrm{QxCN}-\mathrm{T} 2)-m$ & 0.26 & 23.92 & 1.63 & 3.85 \\
$\mathrm{P}(\mathrm{QxCN}-\mathrm{T} 2)-p$ & 0.24 & 26.26 & - & - \\
\hline
\end{tabular}
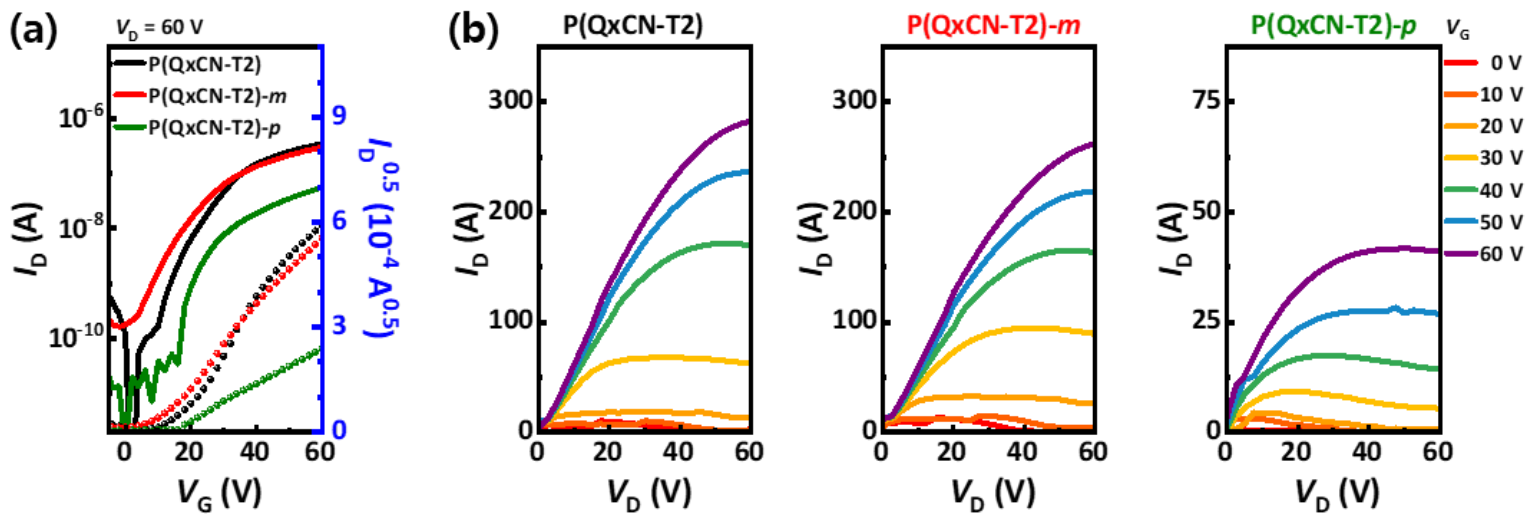

Figure S6. (a) Transfer curves $\left(I_{\mathrm{D}}-V_{\mathrm{G}}\right)$ and (b) output curves $\left(I_{\mathrm{D}}-V_{\mathrm{D}}\right)$ of field-effect transistors made of QxCN-based polymers. 


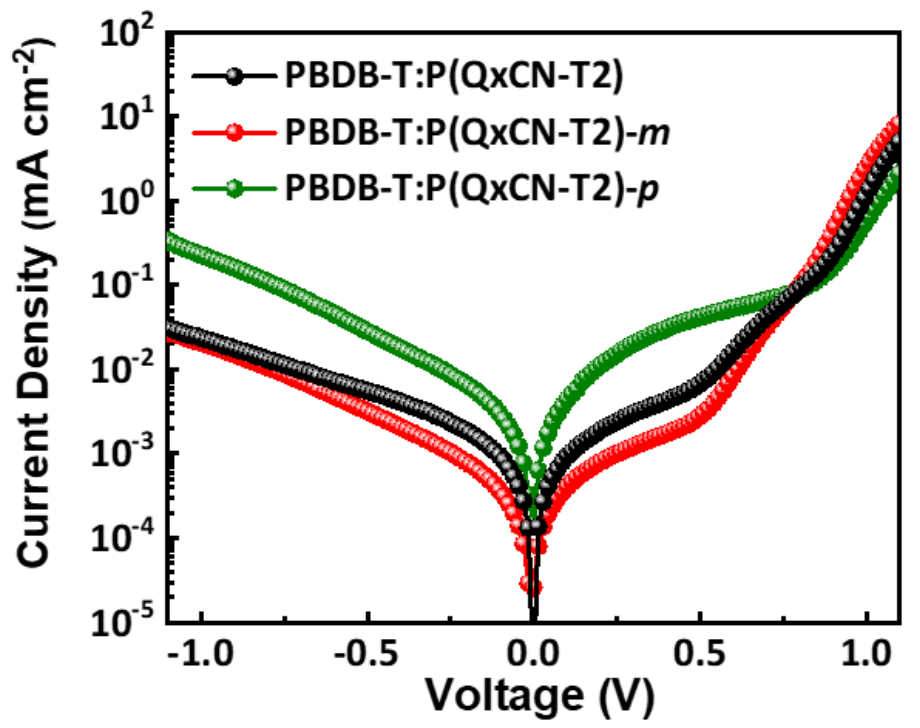

Figure S7. $J-V$ characteristics of all-PSCs in the dark.

Table S2. Electron mobilities measured using SCLC devices based on blend films of QxCNbased $P_{\mathrm{AS}}$ with PBDB-T.

\begin{tabular}{lccc}
\multicolumn{1}{c}{ Active layer } & $\begin{array}{c}\mu_{\mathrm{e}, \text { blend }}{ }^{a} \\
\left(\mathrm{~cm}^{2} \mathrm{~V}^{-1} \mathrm{~s}^{-1}\right)\end{array}$ & $\begin{array}{c}\mu_{\mathrm{h}, \text { blend }}{ }^{a} \\
\left(\mathrm{~cm}^{2} \mathrm{~V}^{-1} \mathrm{~s}^{-1}\right)\end{array}$ & $\mu_{\mathrm{h}, \text { blend }} / \mu_{\mathrm{e}, \text { blend }}$ \\
\hline $\begin{array}{l}\mathrm{P}(\mathrm{QxCN}-\mathrm{T} 2) \\
\text { blend }\end{array}$ & $(1.2 \pm 0.2) \times 10^{-4}$ & $(1.1 \pm 0.1) \times 10^{-4}$ & 0.9 \\
$\begin{array}{l}\mathrm{P}(\mathrm{Q} \text { xCN-T2 })-m \\
\text { blend }\end{array}$ & $(5.4 \pm 0.1) \times 10^{-5}$ & $(1.1 \pm 0.2) \times 10^{-4}$ & 2.0 \\
$\begin{array}{l}\mathrm{P}(\mathrm{QxCN}-\mathrm{T} 2)-p \\
\text { blend }\end{array}$ & $(3.2 \pm 0.3) \times 10^{-6}$ & $(1.2 \pm 0.2) \times 10^{-4}$ & 37.5 \\
\hline
\end{tabular}

${ }^{a}$ The average values were determined from the measurements of more than 10 devices. 

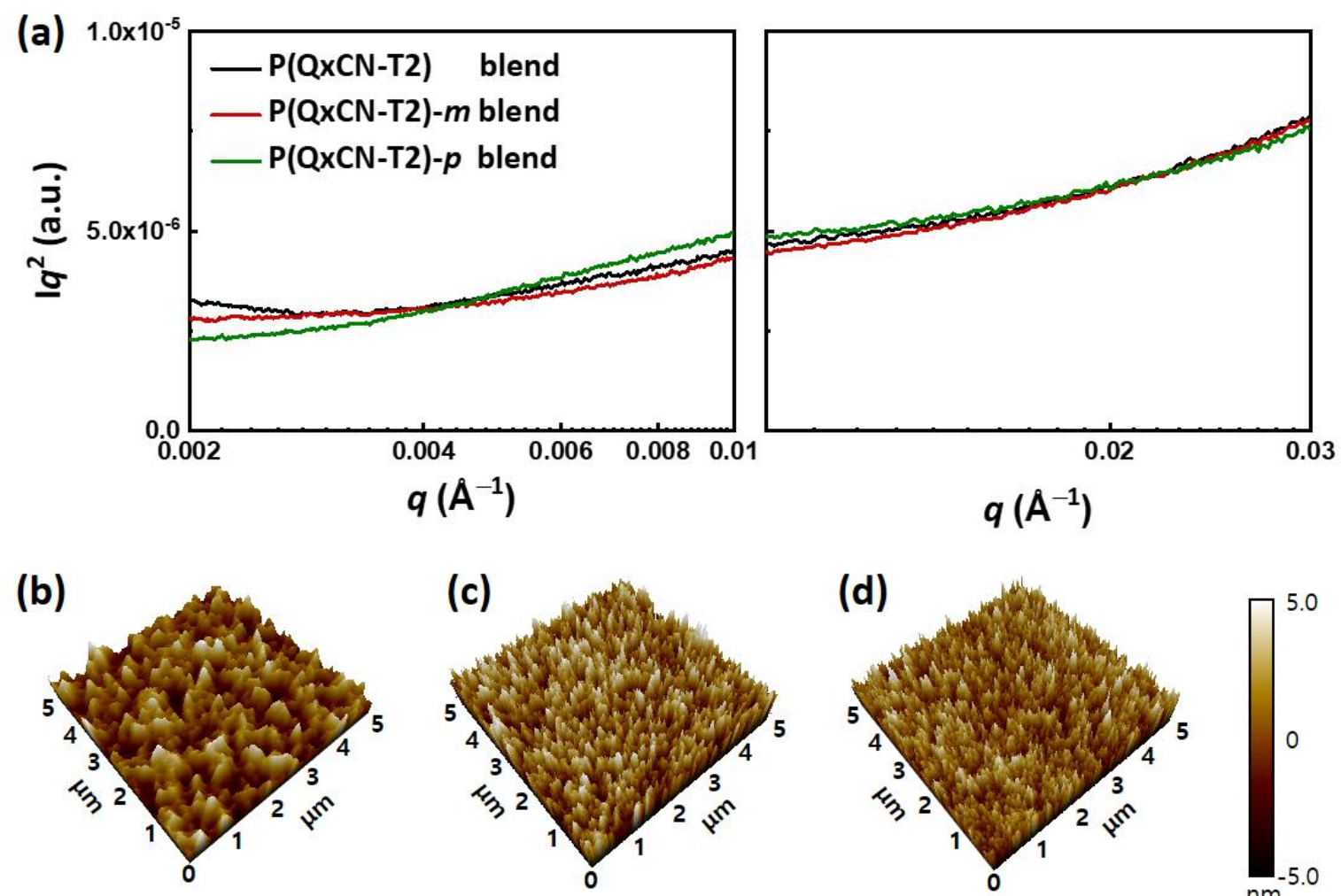

RMS roughness : $1.32 \mathrm{~nm}$ RMS roughness : $1.59 \mathrm{~nm}$

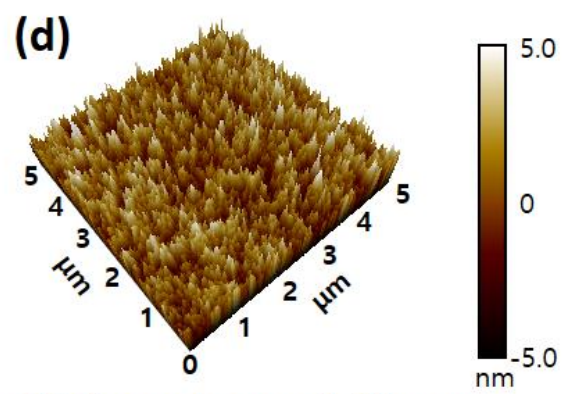

RMS roughness : $1.33 \mathrm{~nm}$

Figure S8. (a) RSoXS profiles and AFM height images of (b) $\mathrm{P}(\mathrm{QxCN}-\mathrm{T} 2)$, (c) $\mathrm{P}(\mathrm{Q} x \mathrm{CN}-\mathrm{T} 2)-$ $m$, and (d) $\mathrm{P}(\mathrm{QxCN}-\mathrm{T} 2)-p$ blend films. 


\section{Reference}

(1) Rivnay, J.; Mannsfeld, S. C. B.; Miller, C. E.; Salleo, A.; Toney, M. F. Quantitative Determination of Organic Semiconductor Microstructure from the Molecular to Device Scale. Chem. Rev. 2012, 112, 5488-5519.

(2) Neese, F. The ORCA Program System. WIREs Comput. Mol. Sci. 2012, 2, 73-78.

(3) You, H.; Kang, H.; Kim, D.; Park, J. S.; Lee, J.-W.; Lee, S.; Kim, F. S.; Kim, B. J. CyanoFunctionalized Quinoxaline-Based Polymer Acceptors for All-Polymer Solar Cells and Organic Transistors. ChemSusChem 2021, 14, DOI:10.1002/cssc.202100080.

(4) Wu, Z.; Sun, C.; Dong, S.; Jiang, X.-F.; Wu, S.; Wu, H.; Yip, H.-L.; Huang, F.; Cao, Y. nType Water/Alcohol-Soluble Naphthalene Diimide-Based Conjugated Polymers for HighPerformance Polymer Solar Cells. J. Am. Chem. Soc. 2016, 138, 2004-2013.

(5) Kim, F. S.; Hwang, D.-K.; Kippelen, B.; Jenekhe, S. A. Enhanced Carrier Mobility and Electrical Stability of n-Channel Polymer Thin Film Transistors by Use of Low-k Dielectric Buffer Layer. Appl. Phys. Lett. 2011, 99, 173303. 